\title{
Indian costumes through the ages - Insights into sartorial choices using mathematical biology
}

Mohan Raghavan ${ }^{1} \&$ M K Raghavendra ${ }^{2}$

25th August 2020

${ }^{1}$ Indian Institute of Technology Hyderabad

${ }^{2}$ HTSR Institute 


\section{ABSTRACT}

Costumes of a civilization are studied as a means of understanding the people, their thinking, tastes and culture. This field has mostly taken a descriptive approach where features are analyzed, compared in detail to glean information about the epoch and culture. In this interdisciplinary study, we propose a novel numerical encoding of costumes based on the interaction of costumes with human anatomy. Using methods from machine classification on a set of costumes from ancient to contemporary periods, we show that costumes of different epochs and cultures are separable in the two dimensional principal component space. We use the Eigen costumes to analyze the immutable similarity in Indic costumes through the ages and the contrasting features between Indic and non-Indic. We further dwell into primary sources to demonstrate that these characteristic features of Indic costumes were very likely considered and deliberate choices in order to induce beneficial effects on prāna in specific, and achieve harmony in Yoga in general. We hope that this work will be a small first step for an alternate way of deriving insights into personal choices, societal trends and cultures using methods from life sciences and computation.

\section{AUTHOR KEYWORDS}

Indian Costumes; Anatomy; Machine Classification; Principal Component Analysis (PCA); Prāna; Yoga; 


\section{INTRODUCTION}

The history and development of Indian costumes have been studied by reputed scholars over the last century. Ghurye ${ }^{3}$ in his magnum opus has described the development of costumes and also compared them with costumes of other civilizations. Studies have also focused on specific periods of Indian history such as Indus Valley Civilization period ${ }^{4}$, Mauryan, Gupta and Kushana period $^{5}$. Analysis of the diverșity of contemporary Indian costume has also been performed $^{6}$. All these studies analyze the aesthetics, tastes, customs of a people. The specific styles of various periods and their evolution are sought to be understood. There is a focus on the styles and their borrowings, hybridization with time and cultural exchanges. The effect of climatic conditions, cultural norms, availability of materials, are considered.

However, the current methods describe garments in cultural and descriptive terms, like scarf, tunics, dhoti, gowns, shirts and trousers. The bewildering variety within each of these costumes is described using several qualifiers such as long short, heavy, light, thick, thin, pretty, decorated and others. This method of description makes it difficult to quantify the similarity or dissimilarity of costumes. It is also difficult to compare costumes of completely different genres.

\footnotetext{
${ }^{3}$ Ghurye, G.S., 1966. Indian costume. Popular Prakashan.

${ }^{4}$ Kenoyer, J.M., 1991. Ornament styles of the Indus valley tradition: evidence from recent excavations at Harappa, Pakistan. Paléorient, pp.79-98.

${ }^{5}$ Pandey, I.P., 1988. Dress and ornaments in ancient India. Bharatiya Vidya Prakashan.

${ }^{6}$ Biswas, A., 2017. Indian costumes. Publications Division Ministry of Information \& Broadcasting.
} 
For instance, comparing a saree with a kimono is difficult as there exists little or no common reference frame. Also the effect of the dress on the human body and its interactions are rarely studied.

Thus in order to provide a universal, quantifiable and consistently applicable vocabulary for describing, comparing and analyzing costumes we propose a framework that uses the interaction of costumes with the human anatomy. Across cultures and geographies, the common thread that binds costumes is that it clothes the musculoskeletal frame of the human body. Thus the anatomy of the human body provides a common reference frame for study of costumes. The subjective feeling of wearing a costume gives us comfort and familiarity. Thus interaction of costume with the body may be an immutable element that resists change.

In this study we describe such a framework for describing a variety of costumes over epochs from ancient to contemporary and from Indic and non-Indic cultures. We apply numerical methods to classify the costumes and analyze the underlying patterns that characterize epochs and cultures. We further seek to understand the motivations that might have guided Indic ancients in making the choices that they made. We try to infer the same from literary sources to see if a coherent picture can be arrived at, that harmonizes the patterns in Indic costumes and Indic philosophy.

\section{METHODOLOGY}


We propose a novel encoding of costume based on its articulation with various features of the human anatomy. The encoded costume database was then subjected to analysis to extract common patterns, differentiating features between various groups of costumes.

For the purpose of this study a costume was defined to be the entirety of clothing and ornaments on a single individual in a given specimen. Multiple individuals picturized in the same photograph or sculpted in the same panel or piece of rock were treated as separate specimens distinct from each other. The encoding was performed based on a given specimen which could be in the form of photographs, sculptures or any other representation. Thus photographs of the same live person on different days or different times were considered different specimens as the costume may have changed in the interregnum. Similar sculptural specimens of the same period and discovered from the same site were still encoded as distinct specimens. Photographs of two specimens likely to have been cast from the same mold were still considered to be distinct as the set of features preserved in each of them might be different. Tools, weapons or other implements in the hands of subjects were not considered a part of the costume.

\section{Encoding of costumes}

The encoding of a costume consists of a tuple representing the articulation of a costume with several points on the human body. We used a set of 46 articulation points on the human body for the purpose of this study. The articulation points were largely chosen based on a study of the various costumes and the parts of the body with which they articulated. The articulation points are depicted in Figure 1. The encoding of a costume is thus a 46-tuple in this scheme and 
specifies the kind of articulation between the costume and each of the articulation points. The tuple representing the costume may be thought of as a feature vector of the costume, in the parlance of data science. The articulation vector of an articulation point is the set of encoding at the articulation point for all costumes.

We identified 5 different types of articulations based on the intensity and focus of articulation. The articulation types are:

\section{Knots:}

These are single points of intense articulation, as in the knot on top of the head, garments tied up in a knot, knot of a bandanna and others. The knots may be on account of tying up the ends of a clothing, or a tied up coiffure at the back or top of the head, or an amulet tied to the forehead or on the arms. Hanging amulets are not considered as knots. Ear rings are considered as knots on account of an implied piercing.

\section{Bands:}

They consist of tight bands around the arms, wrists, hips, loins, forehead. Bands can be created by clothing or jewellery. Chokers, arm bands, wrist bands are created by jewellery. A crown induces a band around the forehead by the articulation of its bottom rim. A tight cuff of a bush shirt on the arm, a tight cuff of a full sleeved shirt on the wrist, a belt on the waist, tightening of strings of a pyjama, a bandanna on the forehead are all considered as bands. 


\section{Drapes:}

A Drape is a less intense articulation brought about by the draping of a scarf, shawl or dupatțā. In addition, a loosely hanging chain around the neck and resting on the breasts, represents a drape at the neck and the pair of breasts. A sacred thread is also considered a drape articulating usually with the left shoulder and right midriffs. An elaborate shawl wending its way over the left shoulder and gently looping around the left arm and hanging over the left forearm would be considered as drape-articulation at left shoulder, left arm and left forearm. In a few cases, the shawl may be drawn taut around the arm. In such a case the articulation at the arm is considered to be like a band, while the articulation at shoulder and forearm are considered drapes. The classification of articulation type is more driven by the intensity of articulation that the form of the articulating cloth or ornament.

\section{Envelopes:}

An envelope is an articulation brought about by a cylindrical piece of cloth around a part of the body. The body of the shirt is an envelope around the trunk, the sleeves are an envelope around the hand. Similarly, trousers represent a pair of envelopes around the legs. Tunics and night gowns are envelopes around both the upper and lower halves of the body. The articulation between an envelope and all articulation points occluded by the envelope is deemed to be of this type. Although drapes and envelopes are both relatively gentle articulations, the primary difference between a drape and an envelope is that the drape represents a consistent and localized articulation due to a narrow and long strip of cloth. Drapes thus induce differential articulation between nearby regions. The envelope is a relatively global articulation and simultaneously 
covers large swathes with similar articulations. However, it must be noted that the articulations induced by the edges of the envelope are considered similar to drapes. For instance, the neckline of a gown is treated similar to a chain of the same shape. Similarly, the edges of the cuff are encoded as bands provided they are tightly bound around the wrist or arm. A blouse tightly fastened around the ribs, just below the breasts is treated as a band around the chest. The hemlines of gowns if free flowing, do not induce any articulations.

No articulation:

Articulation points that do not exhibit any of the previous 4 categories are said to have no articulation.

For more details on classifying articulation types, please see supplementary materials. The differentiation between uniform articulation (envelope) and local differential articulation (drape) is inspired by the general principles of sensory organization where the stimulus at a point is perceived in relation to the stimulus strength in the surrounding areas ${ }^{7}$.

\footnotetext{
${ }^{7}$ Purves, A., Fitzpatrick, H. and LaMantia, M., Williams, 2004. Neuroscience, third edition. Sinauer Associates.
} 


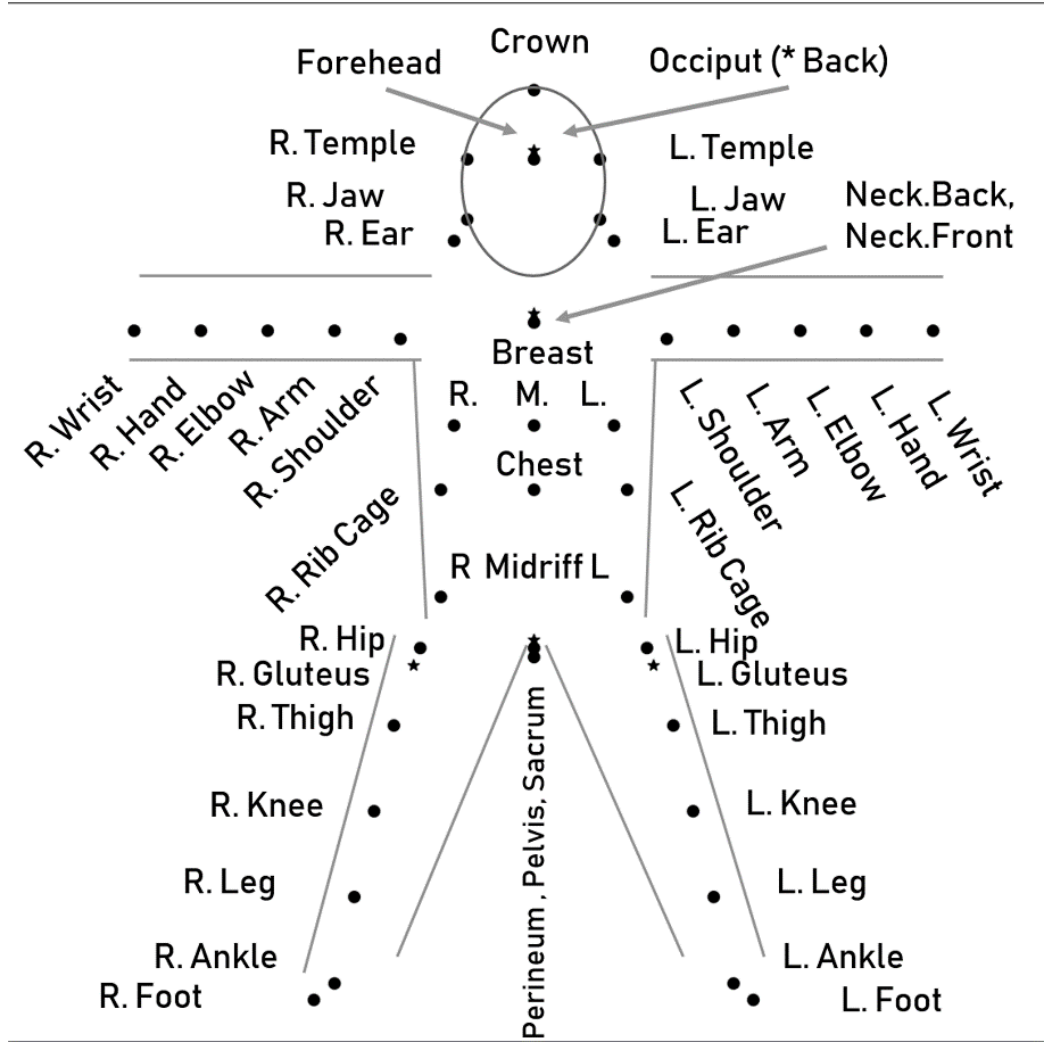

Figure 1: Cartoon of human anatomy with 46 marked articulation points used in the study. R, M, L stand for Right, Left and Middle respectively

When multiple articulation types are present at a single articulation point, the articulation type is chosen to be the one that is most intense among the available options. In the encoding scheme, knot, band, drape, envelope and no-articulation are represented by numerical values 3,2,1,0 and 1 respectively.

\section{Choice of costume specimens}


The costume specimens are predominantly Indian and were chosen to cover a wide range of historical periods starting from Indus Valley civilization and continuing with the Maurya, Shunga, Satavahana, Kushan, Gupta, Vakataka, Pallava, Chalukya, Chandela and the Mughal periods. Similarly, representative samples were also chosen from other ancient civilizations such as Egyptian, Sumerian, Elamite and Assyrian. Samples have also been chosen from the Greek, Roman and Arab costumes. Finally, representative samples from South Indian costumes in traditional and contemporary styles have been used. A relatively larger sample size was used for the Indus valley civilization as most artifacts were partially destroyed and only few articulation points could be retrieved from each. In all about 70 different costume specimens were used in the study. A complete list of the specimens chosen for this study and their sources are provided in the supplementary materials.

\section{Analysis of costume database}

1. We first computed the pairwise correlation between all the normalized (mean $=0$, standard deviation=1) articulation vectors. This pairwise correlation matrix was further used to perform a hierarchical agglomerative clustering of all the articulation points. The dendrogram tree of articulation points was plotted to graphically analyze the correlation structure between all the articulation points

2. Principal component analysis was performed on the costume database to obtain a set of Eigen costumes. Projections of feature vector representing a costume were computed along the 
direction of Eigen vectors/ Eigen costumes. Using the projections along the top two Eigen costumes, scatter plots of the specimens were computed in the principal component space.

3. The Eigen costumes were plotted as an image to analyze the features emphasized or deemphasized by the various Eigen costumes.

Principal component analysis is a mathematical technique used to separate a set of data points so they are distinguishable. It is also used to identify strong patterns in a group of specimen points.

\section{RESULTS}

Correlation structure of articulation points provides a culture agnostic vocabulary for

\section{description of costumes}

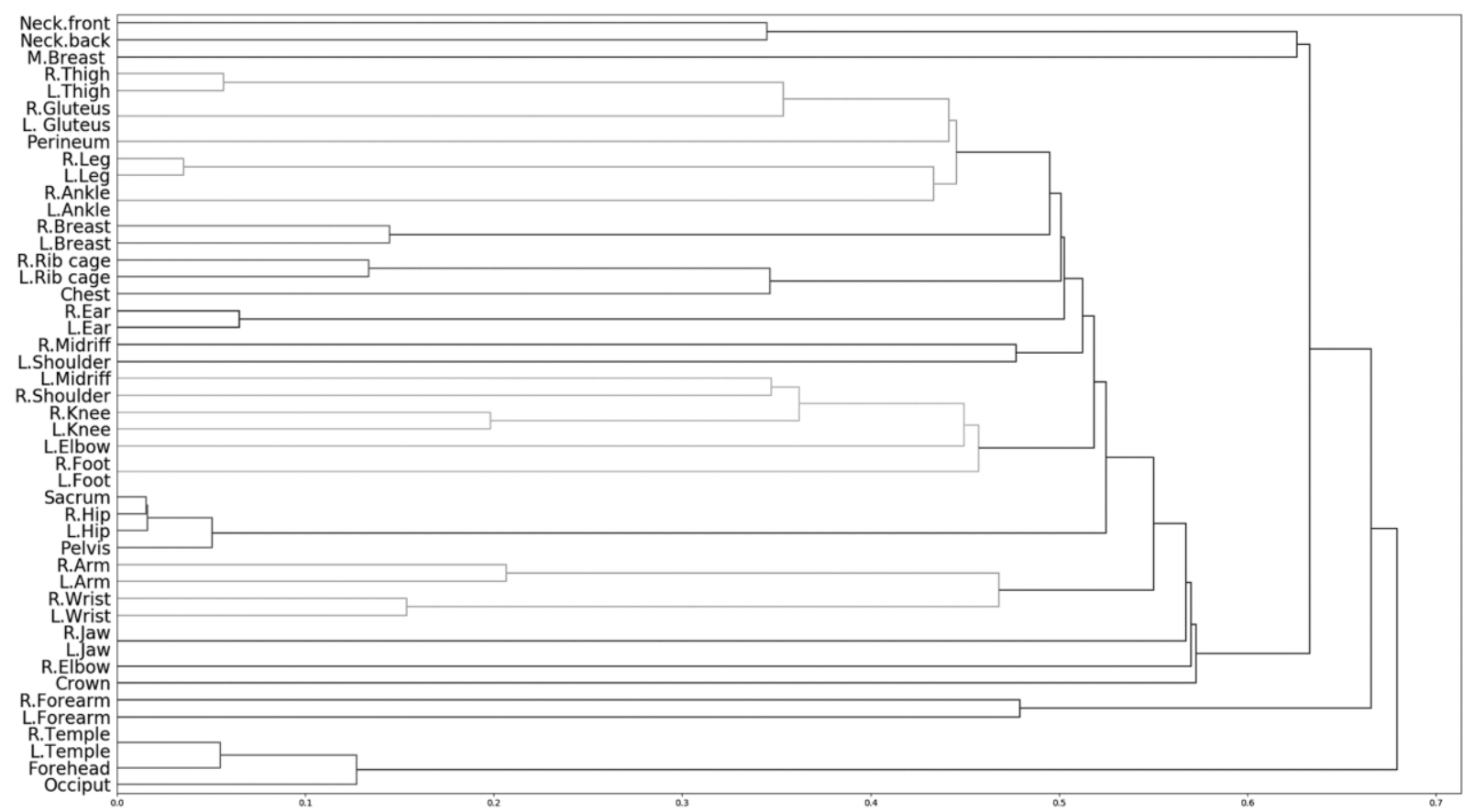


Figure 2. Dendrogram of all articulation points. On the left margin are the various features (articulation at points) based on which costumes are encoded. The correlation structure of these features across all specimens are used to create this tree. Moving left to right along the tree, at each step, two features or feature groups merge to form a larger feature group, until all features have merged at the right extreme. At each step to the right, features with strongest correlations are merged

Analysis of the correlation structure of articulation points reveal interesting patterns. The full dendrogram with hierarchical clustering is shown in Figure 2. We see that the forehead, occiput and the temples are strongly correlated and form a unit. This is evidently because of head dresses, headbands, crowns that go around the head articulating with these points. Other such units formed comprise of the hips, sacrum and pelvis (due to girdles, top of dhotis, strings of pajamas and churidars), neck and middle of the breasts (due to the chains, collars of gowns and tunics), chest, rib cages (due to chest bands and hem of blouses). Correlated articulation units are formed between bilateral body parts like left and right arms, wrists, forearms, elbows, legs, thighs, feet, breasts and buttocks. A notable anti-symmetric unit comprises of left shoulder and right midriff due to cross belts, scarves, uttarīya or sacred thread.

These expected correlation patterns primarily validate the fidelity of our costume encoding scheme. Secondly, these correlated units also allow us a uniform vocabulary to define costume patterns in terms that are agnostic to culture, genre, time, ethnicity and geography. 


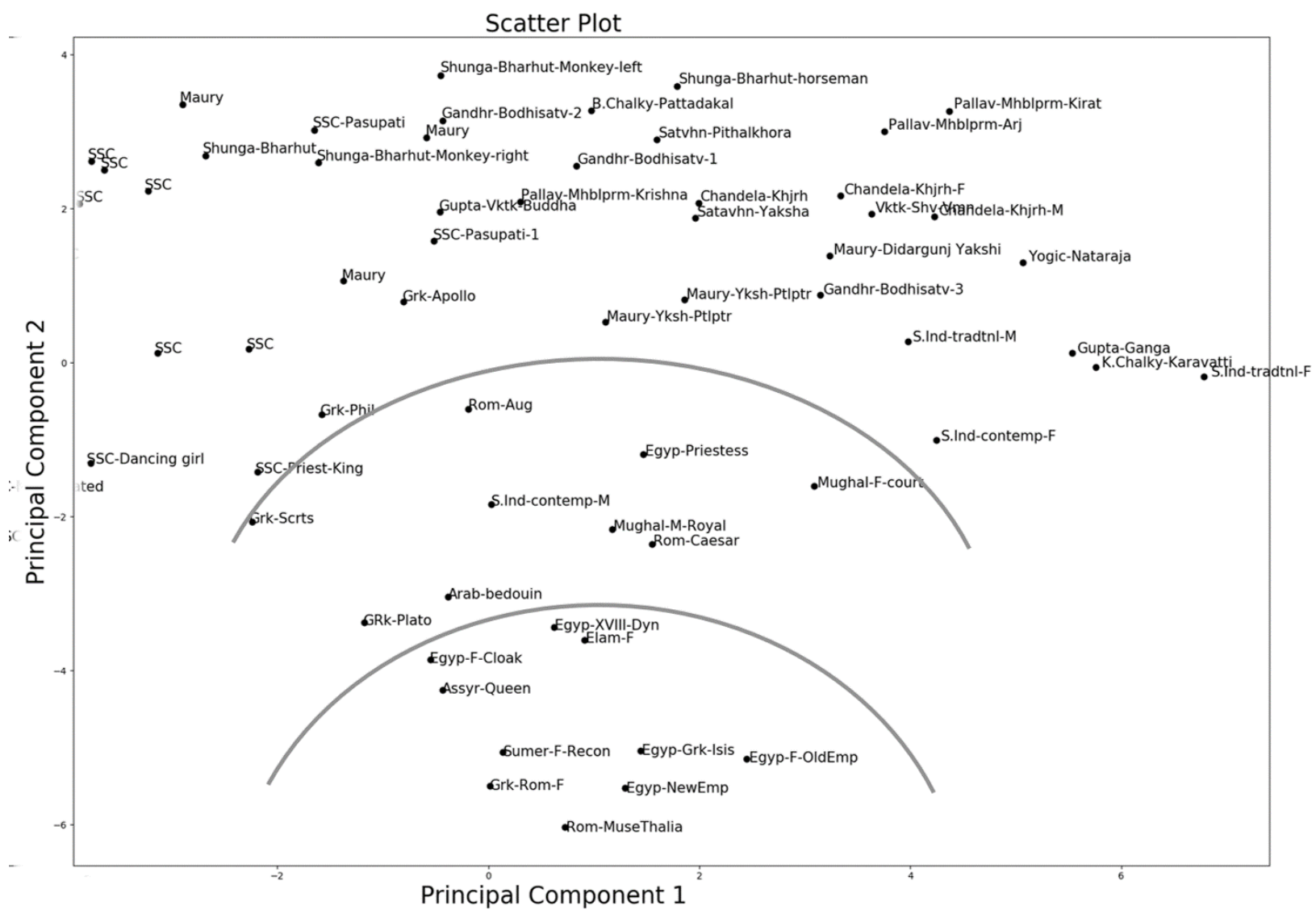

Figure 2 Scatter plot of costumes on Principal component plane. Every costume is plotted at a coordinate given by the projection of its encoding along the principal component axes. A part of the scatter plot on extreme left consisting of a few SSC (Sindhu Saraswati Civilization or Indus Valley Civilization) data points have been cropped to increase overall image size. The two arcs are drawn in order to show that the various epochs and cultures are largely separable on this plane. The two arcs divide the plane into three concentric sectors. It may be noted that the Indic costumes are largely spread along the topmost sector from left to right with earlier epochs on the left and later more refined ones on the right. Bottom sector houses the Egyptian, Sumerian and Elamite costumes. The middle sector contains mostly Greek, Roman and Arab costumes with a few stray exceptions from Indic and Egyptian sides 
Indic costumes through the ages form a continuum and have patterns distinct from that of other cultures

The results of the principal component analysis show that the percentage variance of data that is explained by the first 5 Eigen values is less than $50 \%$. About $75 \%, 90 \%$ and $98 \%$ of the variance can be explained by the first 10,15 and 25 Eigen values respectively. This indicates, not surprisingly, that set of costumes are very diverse and cannot be described using very few features. But the set of 46 articulation points can be reduced to about 10 composite features to account for up to $75 \%$ of the variance.

But a scatter plot (Figure 2) of the costumes on the first two principal component axes throws up interesting results. From left to right on the horizontal axis are arranged Indic costumes from the earliest to the latest times. The Indus Valley civilization is on the extreme left with a few costumes (Pasupati seals) found further to the right. Mauryan costumes are found slight to the right with a few of them straying far to the right. These are the exquisitely sculpted Didargunj Yakshi and the Patliputra Yakshas. The much later Kalyani Chalukyan costumes and that of Khajuraho (Chandela period) are on the extreme right. The Gupta, Vakataka and the early Badami Chalukyan costumes are spread over the middle. Thus there is a continuum starting from Indus Valley all the way to the contemporary times. 
The vertical axis shows a significant separation between the Indic costumes on the top half and others on the bottom half. The civilizations of Egypt, Asyrria and Sumeria are right at the bottom, while the Greco-Roman costumes and a few from the Indus Valley civilization fall in the middle. The Mughal costumes which are a hybrid with an Indic element also find a place in the middle. The Greek and Roman costumes form a sort of bridge between the top and bottom halves with some of them strewn amidst the Indic cluster and some further deep down with the Egyptian.

Considering the scatter along both axes, it may be said that the Indic timeline is stretched in an arc passing from left, through the top and right. The older non-Indic civilizations are at the bottom with a diffuse scatter upwards towards the Indic cluster. The Greek, Roman, some Indus Valley and Mughal costumes act as bridges between Indic and non-Indic costumes.

\section{Putative skeleton of an Indic costume}

While the scatter plots along principal axes were effective in separation of the historical phases and cultures, it is important to analyze the features based on which this separation has become possible and the salient features of the different clusters. In particular, the features that seem to resolve time along the horizontal axis and cultures along the vertical axis are of significant interest. 
We seek to understand this through the analysis and interpretation of the Eigen vectors that form the horizontal and vertical axes. The Eigen vectors, just like feature vectors can be interpreted as the encoding of a costume. Thus the principal component analysis throws up a series of Eigen vectors, in this case to be interpreted as Eigen costumes. The scatter plot essentially composes every costume as a weighted sum of the two Eigen costumes. Thus a costume at coordinates (x, y) on the scatter plot implies a costume constructed as

$\mathrm{x} *$ Eigen-costume-1 $+\mathrm{y} *$ Eigen-costume-2

It must be noted that since Eigen costumes are now encoded as a tuple representing intensity of articulation at various points, addition or subtraction of Eigen costumes implies addition or subtraction of articulation intensities at the respective points. While a weighted sum of all the Eigen costumes produces the exact original encoding of every costume, the weighted sum of just the first few Eigen costumes constructs the salient features only. In this case, the scatter plot describes the extent of the presence of patterns of Eigen vectors 1 and 2 . The scatter plots described in the previous result tells us that this reconstruction is sufficient to reasonably distinguish between Indic and non-Indic cultures and also differentiate between phases of Indic costumes. The first two Eigen costumes are depicted in Figure 4. In this figure, dark circles represent articulation points that are emphasized - meaning intense articulation. Gray circles represent de-emphasized articulation points. These are points with negative weights in the Eigen costume and when added to other Eigen costumes reduce the articulation intensity. In simple terms dark circles may be understood as saying "There should be articulation at this point" and 
gray circles as saying "There should NOT be articulation at this point". The larger the size of the marker greater the emphasis or de-emphasis as the case may be.

We see that the first Eigen costume emphasizes almost all the articulation points to various extents. It is almost devoid of any de-emphasis. It places large emphasis on the lower part of the body, notably the thighs, legs and ankles. On the upper extremities significant emphasis is placed on arms and wrists. On the trunk, the breasts, sides of the ribcage and the chest are emphasized. There is moderate emphasis on the left shoulder and right midriff, with little or no emphasis on the right shoulder and left midriff. The ears and crown are emphasized. Overall, this Eigen costume favours richness in costume that articulates with almost all major articulation points. It is this facet that allows it to differentiate time in historical terms. Within the Indic civilizations, the old Indus valley period sees minimal costumes and the costumes get richer and cover more parts of the body with time. The fact that most of Indus valley artifacts are either busts, or decapitated torsos or small figurines with barely differentiable anatomies, plays a role in the unusually low score along the horizontal axis for this period as compared to the Egyptian or Sumerian costumes where we have fuller reconstructions.

The second Eigen image is more likely to give us the broad contours of an Indic costume as it separates the Indic from the non-Indic costumes along the vertical axis of the scatter plot. This Eigen costume is more selective than the first and places significant emphasis on the ears, articulation points around the pelvic girdle and around the head through forehead, temples and the occiput. This agrees with our intuitive understanding that the Indic costumes usually have a 
pronounced band around the hips in the form of mekhala or other similarly articulating accessories. The band around the forehead in the form of a crown or head-dress is mostly present. Probably even more important than the emphasized points are the ones that are deemphasized as they tell us the features that should be excluded in order to score high on this vertical axis where Indic costumes reside. Firstly, the lower extremity from the knee downwards are de-emphasized. The knees and the foot are very strongly de-emphasized. As we can see, there are hardly any costumes that form bands, drapes or knots at the knee. The only articulation that is commonly found articulating at the knee is the envelope and it is this feature that is being strongly rejected by this Eigen costume. The presence of flowing robes on the lower part of the body are a recurrent feature in almost all non-Indic costumes, while older Indic costumes rarely fall below the knee. In the later and richer costume, notably the south Indian traditional costumes in the form of a kacch $\bar{a}$ which covers the entire lower extremity, there are strong Indic features of tight band around the waist, band like formation around the thighs, upper garment in upavit $i$ (left shoulder to right midriff). The absence of footwear in Indic sculptures presumably because of the sacred nature of sculpture and art has also been observed previously ${ }^{3}$. A strong deemphasis on the left elbow may be noted. As bands and knots are not possible, the only features that are sought to be rejected are the envelopes represented by full sleeves (as in Mughal costumes) and the fancy drapes that loosely wend their way around the left hand as seen in Roman and Greek costumes. Finally, there is a strong rejection of articulation points on the diagonal pair of points consisting of right shoulder and left midriffs. Taken together with the moderately strong preference in the first Eigen costume for the other diagonal involving left shoulder and right midriff, the costumes with drapes from left shoulder to right midriff and 
exposed right shoulder and left midriff are favoured by this Eigen costume and will experience movement towards the Indic cluster on the scatter plot.

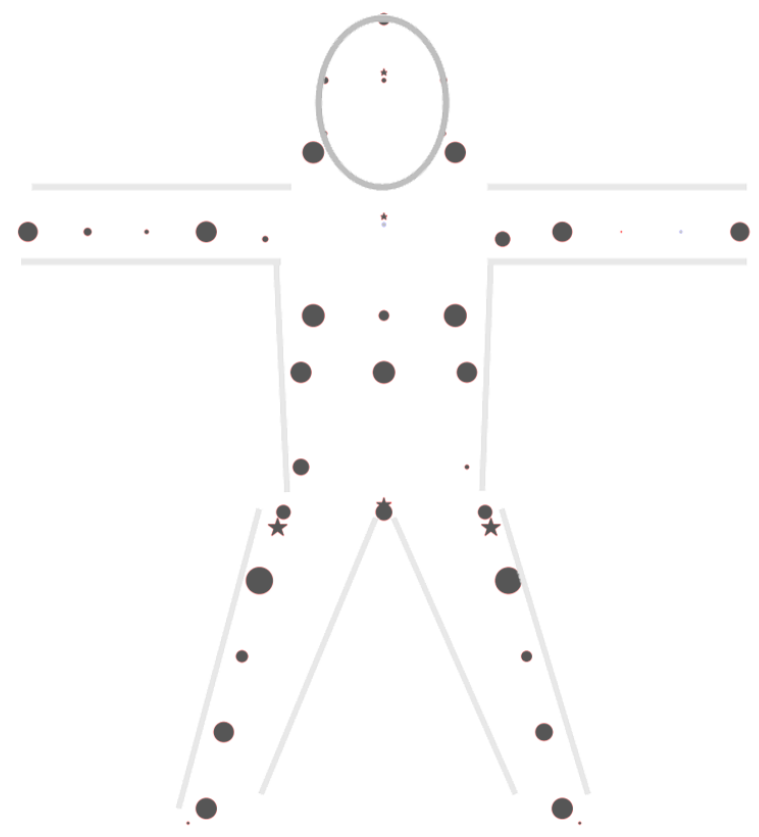

(a)

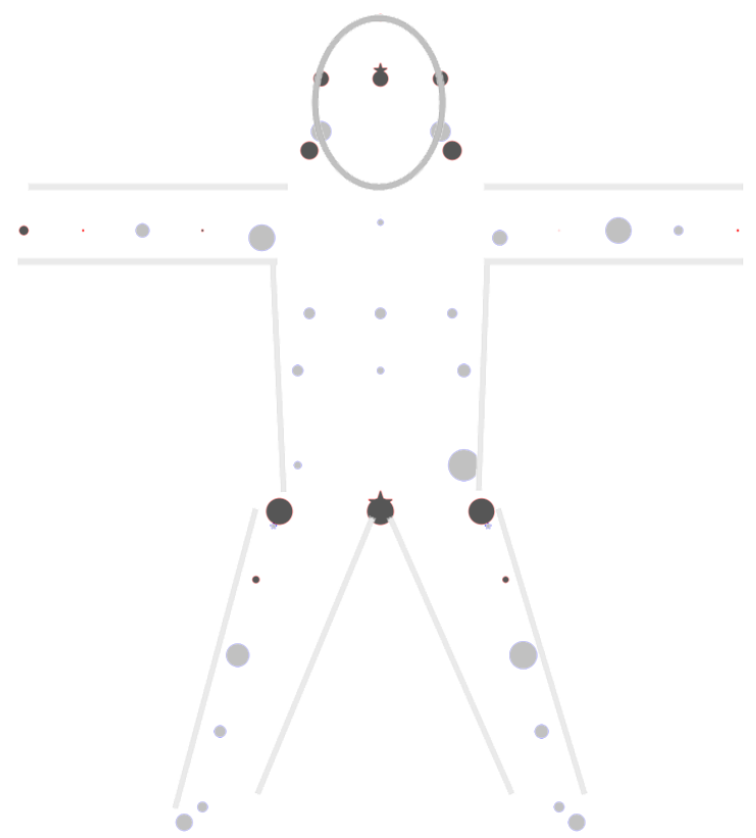

(b)

Figure 4 Eigen vectors or principal components depicted as an Eigen costume. (a) First

Eigen costumes (b) Second Eigen costume. The dark circles represent points of articulation and the gray circles are points of de-articulation or negative articulation. The size of the circles indicate intensity of articulation or de-articulation. Characteristic features of Indic costumes are visible in (b) in the form of intense articulation / emphasis at the pelvic girdle, around the forehead and a de-emphasis on the anti-diagonal defined by right shoulder and left midriff. The second Eigen image is more likely to give us the broad contours of an Indic costume as it separates the Indic from the non-Indic costumes along the vertical axis of the scatter plot. This Eigen costume is more selective than the first and places significant emphasis on the ears, articulation points around the pelvic girdle and around the head through forehead, temples and 
the occiput. This agrees with our intuitive understanding that the Indic costumes usually have a pronounced band around the hips in the form of mekhala or other similarly articulating accessories. The band around the forehead in the form of a crown or head-dress is mostly present.

\section{DISCUSSION}

It is clear from the previous analysis that Indic costumes have a significantly higher proportion of some articulatory patterns that distinguish them from other cultures. These patterns are

1. Preferential articulation on the diagonal from left shoulder to right midriffs and nonarticulation of the anti-diagonal from right shoulder to left midriff

2. Articulation around the pelvic girdle or waistbands

3. Articulation around the forehead and earrings

4. Relative absence of envelopes

\section{On the Yajñopavitam or sacred thread in Indic costumes}

The Yajñopavitam is thought to be a late innovation ${ }^{8}$ from early centuries CE. But here we see that the Yajñopavittam and Uttarìya as a drape from left shoulder to right midriff are identical in

${ }^{8}$ https://www.harappa.com/slide/priest-king-mohanjo-daro 
their articulatory pattern. The latter is attested very early in Indic history starting from the costume of Priest-king ${ }^{8}$ and the seated male figure ${ }^{9}$ from the Indus valley and the later Yakshas of Pataliputra discovered by Cunningham ${ }^{10}$. Thus it is very likely that in earlier times, the Uttarīya played the role of a Yajñopavītam for the performance of a Yajña and later on it was explicitly created in thread as we know it today. This proposition is supported further by the fact that even to this day in traditional south Indian parlance, the Uttariya worn in this fashion is considered as the tritiya Yajñopavitam or the third sacred thread. Further, the connections of the upper garment with the Yajña lend credence to this hypothesis. The upper garment or adhivāsa is a part of the performance of sacrifice ${ }^{11}$. It is verily a representation of the Yajña itself and it is said that one who covers himself with Adhivastra of yajña achieves happiness ${ }^{12}$.

Be that as it may, it is crucial to ponder as to why this particular style was adopted preferentially. Was it a conscious choice or a chance event? The philosophy and practice surrounding the Yajñopavitam suggests that it was a conscious choice. The left shoulder-right midriff style is called upaviti and is adopted during the performance of a Yajña for the devas (the anti-diagonal Prācinā viti style is used for a Pitr Yajña). The devas are associated with the spiritual path called

${ }^{9}$ https://www.harappa.com/slide/male-front

${ }^{10}$ Cunningham, A., 1882. Report of a Tour in Bihar and Bengal in 1879-80, from Patna to Sunargaon.. (Vol. 15). Office of the Superintendent of Government printing.

${ }^{11}$ The Rgveda, 1.162 .16

12 The Rgveda, 8.26.13 
the arcirādi mārga, while the Pitṛs with the dhümādi mārga ${ }^{13}$. Thus it is strongly possible that articulation along the two diagonals were in some way associated with the deva and pitr Yajña and the associated paths-mārga. The clues to this relation may be found in the pāśupata brāhmanopanișat of the Atharva Veda which states that the prāna traverses a path between left shoulder and the right waist 'vāmabāhu dakșinakatyoramtaścarati hamsaḥ" ${ }^{14}$. That the articulation is related to the movement of Prạnas in a desired manner is supported by the fact that in Hindu iconography the sacred thread is represented in the form of a serpent - presumably the prāna śakti or kuṃdali sarpa. During the investiture of the sacred thread, the mantras uttered claim that the sacred thread is verily the Brahman himself and enhances $\bar{a} y u h$, which in turn is again related to the prāna $a^{15}$. The hypothesis linking the sacred thread to prāna, also supports our earlier assertion that Yajñopavitam and the upper garment are interchangeable and served the same purpose.

\section{On the waist band or mekhalā in Indic costumes}

The mekhalā as an explicit ornament is attested from the Mauryan times in the Didarganj Yakshi, through the Shunga and Kushan period is still a part of traditional costumes to this day. In our

${ }^{13}$ brhadāranyaka upanișat - 6-1-14-15

${ }^{14}$ pāśupata brāhmaṇopaniṣat, 25

${ }^{15}$ Yajñopavìtam paramam pavitram prajāpateh yatsahajam purastāt āyușyamagryam pratimam ca śubhram Yajñopavītam balamastu tejạ̣ 
scheme of classification, a mekhala belongs to a class of costumes that are worn around the pelvic girdle. In Indic costumes, lower garment is almost always anchored from the waist forming a mekhala , while in specimens of Egyptian, Arab and Sumerian costumes the tunic is also anchored from the shoulders, breasts or the rib cage (Figures 5, 9-11, 16 in Ghurye $1966^{3}$ ). Thus use of mekhalā is not an inevitable choice and likely a conscious one in Indic context. Adorning a mekhala is a vedic rite and enjoys a pride of place in the atharva veda with an entire süktam devoted to the mekhala ${ }^{16}$. The mekhalā is said to bestow on the wearer victory over death, wisdom, prowess and the ability of indra. It is called as the weapon of Rṣi s and capable of slaying heroes(demons). All of these descriptions are consistent with the concept that the mekhala is intended as a weapon for the one engaged in inner pursuits (the Rṣi ) whom it protects against demons, just as indra subdues vrrtra. The demons that terrorize the Rṣi s may be understood as internal distractions or blocks to spiritual practice. How the mekhala achieves the wondrous feats of slaying demons is explicitly set forth in the yajurāranyakam where it is said to harness for the wearer, the power of the $\operatorname{prannas~}^{17}$. The pelvic girdle may be recognized as a form of uḍ̂̀yana bamdha. The three bamdhas if achieved help an aspirant to achieve liberation ${ }^{18}$.

\section{On headband and rings in Indic costumes}

\footnotetext{
${ }^{16}$ Atharva Veda, Shounaka rescencion, 6.133

17 “Prāṇāpānābhyām balamābharantī” - Ekāgnikāṇḍe dvitīya praśnah

${ }^{18}$ hațhayoga pradīpikā - 55
} 
The band around the head with a pronounced amulet functioning like a knot on the forehead is seen in the priest-king ${ }^{8}$ statue of Indus valley civilization. This exact ornament is still in use in ceremonial occasions in southern India under the name bāsimga. Other forms of this articulatory patterns are crown base and turbans. The forehead-amulet applies intense articulation close to the forehead above the mid-point of the brows, well known as ājñā cakra and hence significant from the point of view of Yogic practice. It is also the point where the bimdi or the bindu or dot is applied on the forehead. The piercing of the ear is one of the samskäras called karnavedha. While it is often claimed to be of extra-Vedic origin, it is said to impart a beneficial effect on the wearer $^{19}$

\section{Immutable features of Indic costumes and the connection with Yoga}

It may be noticed in the preceding paragraphs that all the articulations studied viz, the pelvic girdle, diagonal left shoulder - right midriff and the forehead have been intricately linked to the movement of prānas and with Yoga. Thus it may be said that the single most important motivating factor for the design of Indic costumes is as an aid in Yoga and enabling a favourable movement of the prānas. The Yoga shastras talk about three baṃdhas, mūla (pelvic), uḍ̣īyāna (stomach) and the jālamihara (neck). A number of other bands are commonly found in Indian costumes, the bands around the arms, wrists, loins (mülabamdha) and just below the rib cage (another form of uḍ̂̄yana bamdha). These were not identified as unique features in the aforesaid

\footnotetext{
${ }^{19}$ Rangapriya Sri Srih, 2014. Samskaras-1, Astangayoga Vijnana Mandiram, pg 477
} 
analysis as they were indistinguishable from other features like the tight sleeves around arms or wrists or the fastening of blouses. But it is only in the Indic civilization that these bands at different locations in the body have been used explicitly other than for fastening costumes. This trend has been noticed even as far back as the Indus Valley civilization where the presence of bangles and armbands are a distinguishing feature with respect to other contemporary civilizations ${ }^{4}$. Almost all of the important features of Indic costumes may be seen in the image of natarāja as depicted in southern India [Figure in supplementary materials]. Nataraja's image together with the pose, costume and ornaments are together widely believed to be the purest embodiment of Yoga $^{20}$. In our scatter plot of Figure 2, the natarāja costume is found in the top right of the Indic arc, showing that it is rich and well developed (high score on Eigen costume 1) and at the same time quintessentially Indic (high score on Eigen costume 2).

In terms of neurophysiology, articulation of parts of the body result in patterned somatosensory and/or proprioceptive input to the spinal cord. The spinal cord is the basis for yoga and its experiences. Thus it is no surprise that Indic thinking and philosophy placed a large emphasis on costumes interacting with the human body over and above the aesthetics.

\section{Principles for contemporary evolution of costume}

${ }^{20}$ Chamu, S.V., 1982. The Divine Dancer. Astanga Yoga Vijnana Mandiram. 
However contemporary Indian costume often dilutes from the ideal, driven by the demands of aesthetics, convenience and others. In Figure 2, it may be seen that the South Indian contemporary male costume (S.Ind-contemp-M) sits close to the middle of the scatter plot surrounded by the Greek, Roman and Mughal. However, incorporating a diagonal element and reinforcing the waist and thighs can make the South Indian male move closer to the Indic cluster and South Indian male traditional costume (S.Ind-trdtnl-M). The framework proposed in this study can enable a conscious and systematic design paradigm that fuses the traditional elements with newer contemporary designs.

\section{Relation between Indus Valley, Vedic and other Indo European costumes}

Amongst the Indus Valley specimens except the Priest-King, the seated male torso and the two Pasupati seals, others were figurines probably used as toys or holders for lamps or such. In the scatter plot of Figure 2, the Priest-King and the seated male torso (cropped on extreme left) are closer to the statues of Greek philosophers. But the Pasupati seals are almost indistinguishable from the later Mauryan and Shunga periods. It could be that the Pasupati seals represent an idealized depiction based on the philosophy and their spiritual practices, while the priest-king represents a more pragmatic costume. With time, the ideal features were probably incorporated increasingly in Indic life, while in other Indo European stock it took a turn towards pragmatism and convenience. Even then, the costumes of Greek philosophers preserve some essential Indic features such as the waist band (a less intense version) and the left shoulder right midriff diagonal. Given the paucity of good quality life like specimens from Indus Valley, the presence 
of the diagonal articulation in both the specimens indicates a very high probability that this was an essential aspect in the Indus Valley civilization.

\section{CONCLUSION}

We believe that this study opens up new vistas for the study of Indian costumes and culture in general. The combination of scientific experiments, numerical quantification followed by analysis using first principles of Indic philosophy along with a reading of primary texts and sources is a potent method for understanding Indic culture. We also believe that the results presented in this work could open up further studies for understanding the implication of sartorial choices from a neurophysiological perspective.

\section{ACKNOWLEDGMENTS}

The authors express their heartfelt gratitude to aștāingayoga vijñāna mandiram for their study materials and guidance on a scientific treatment of Indic culture starting from 'first principles' which played a crucial role in developing the study paradigms, results and analysis produced in this paper. 